\title{
Economic impact of traumatic spinal cord injuries in the United States
}

\author{
Christopher H. Merritt, Matthew A. Taylor, Caleb J. Yelton, Swapan K. Ray \\ Department of Pathology, Microbiology, and Immunology, University of South Carolina School of Medicine, Columbia, SC \\ 29209, USA.
}

Correspondence to: Prof. Swapan K. Ray, Department of Pathology, Microbiology, and Immunology, University of South Carolina School of Medicine, 6439 Garners Ferry Road, Columbia, SC 29209, USA. E-mail: swapan.ray@uscmed.sc.edu

How to cite this article: Merritt CH, Taylor MA, Yelton CJ, Ray SK. Economic impact of traumatic spinal cord injuries in the United States. Neuroimmuno/ Neuroinflammation 2019;6:9. http://dx.doi.org/10.20517/2347-8659.2019.15

Received: 17 Apr 2019 First Decision: 3 Jun 2019 Revised: 6 Jul 2019 Accepted: 8 Jul 2019 Published: 20 Jul 2019

Science Editor: Athanassios Kyritsis Copy Editor: Jia-Jia Meng Production Editor: Jing Yu

\begin{abstract}
Individuals having sustained traumatic spinal cord injury (TSCI) in the United States are living longer as compared to historical trends, thanks to an ever-evolving understanding of the nature of this injury. Despite this, multiple barriers to care for TSCl patients remain including variations in government-issued veteran insurance, privatized insurance, and among uninsured individuals. The United States alone experiences 12,000 new TSCl cases every year, many of these are found to occur in a growing proportion of elderly individuals. It is crucial to understand both the short-term direct costs as wells as the long-term rehabilitation costs required by these TSCl patients. The lifetime financial burden for those having sustained a TSCl can be immense for patients, insurance companies, and hospital systems alike. Among those with $\mathrm{TSCl}$, re-hospitalization rates are high, leading to increased healthcare resource utilization within this specific patient population. Costs can quickly balloon into hundreds of thousands of dollars and cause a profound financial burden for these patients. This review article seeks to communicate an understanding of the current financial landscape surrounding TSCI patients. The authors will also examine the costs of acute emergency room surgical care such as American spinal injury association grade, hospital length of stay, as well as the timing delay between injury and surgical decompression. Long-term costs associated with $\mathrm{TSCl}$ such as rehabilitation, care of secondary comorbidities, and post-injury employment prospects will be examined as well. These costs will be framed from the patient's perspective as well as from both the hospital and insurance company's perspectives. It is hoped a complete understanding as to what makes TSCI such a medically and financially burdensome injury will allow for improved healthcare resource utilization in this population.
\end{abstract}

Keywords: Traumatic spinal cord injury, healthcare resource, American spinal injury association grade, hospital length of stay, rehabilitation, post-injury employment

Cc) (i) The Author(s) 2019. Open Access This article is licensed under a Creative Commons Attribution 4.0 International License (https://creativecommons.org/licenses/by/4.0/), which permits unrestricted use, sharing, adaptation, distribution and reproduction in any medium or format, for any purpose, even commercially, as long as you give appropriate credit to the original author(s) and the source, provide a link to the Creative Commons license, and indicate if changes were made.

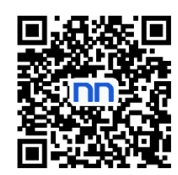




\section{INTRODUCTION}

To begin a discussion of the economic impact of traumatic spinal cord injury (TSCI), it becomes necessary to first have an understanding of the epidemiology and disease burden of TSCI. TSCIs are sustained following major traumatic events, such as falls, motor vehicle accidents, or acts of violence. TSCIs are life-changing, economically impactful traumas that are estimated globally to affect 13 new individuals per 100,000 per year. But this incidence was found to double in North America, affecting nearly 26 new individuals per 100,000 per year ${ }^{[1]}$. The National Spinal Cord Injury Statistical Center, which is both the longest running and largest database containing the specifics of TSCIs in the United States, estimates the incidence of new TSCIs to be roughly 40 cases per one million in the United States, or roughly about 12,000 new cases per year ${ }^{[2]}$. The incidence of TSCI in the United States has historically been held constant, with the largest increases in incidence being observed in the elderly population in the specific context of an increase in the number of falls as an individual ages ${ }^{[3,4]}$. The prevalence of TSCI in the United States is estimated to be approximately 273,000 , within a range of 238,000 to $332,000^{[2]}$. Within the prevalent population as a whole, more severe injuries were observed in younger individuals as compared to those living to older age with incomplete and/or lower level injuries with resulting high degrees of independence $^{[5]}$. The average age at the time of spinal cord injury is estimated to be 42.6 years of age with males accounting for $80.7 \%$ of new cases, vastly outnumbering their female counterparts.

Those with TSCIs have recently been found to be living longer, when compared to historical trends ${ }^{[6]}$. Vehicle crashes remain the leading cause of injury, followed by falls, and then acts of violence (i.e., gunshot wounds) [Figure 1] $]^{[2]}$. The neurological deficits sustained following a TSCI are categorized by its corresponding American Spinal Injury Association (ASIA) score, ranging from A to E with A indicating profound deficit and $\mathrm{E}$ indicating normal function [Table 1$]^{[7]}$. The extent of injuries varies as well, with incomplete tetraplegia being the leading extent of injury, followed by incomplete paraplegia, complete paraplegia, and finally complete tetraplegia [Figure 2] $]^{[2]}$. The limitations on an individual's activities of daily living were found to be largely determined by the location and completeness of the injury sustained, where total hours of care were dependent upon injury level and severity ${ }^{[8]}$. TSCIs exact a heavy financial burden both in the acute care setting as well as within the context of longer-term rehabilitation that often follows the initial injury ${ }^{[9]}$. The costs associated with TSCIs are greatly affected by both the patient's extent of injury and subsequent degree of disability. Unsurprisingly, the overall life expectancy for those individuals sustaining a TSCI remain significantly below the average life expectancy in the United States ${ }^{[10]}$. An understanding of the epidemiological burden of TSCI in the United States warrants a further discussion on the cost, reimbursement, and subsequent disability associated with such an economically, medically, and psychologically impactful event.

\section{ACUTE CARE COSTS FOLLOWING TRAUMATIC SPINAL CORD INJURY}

Immediately following a TSCI, the vast majority of patients will promptly seek medical care consisting of both surgical stabilization and vertebral decompression ${ }^{[1-14]}$. The high acuity of TSCIs often exacts a heavy financial burden in addition to a life-altering disability for these patients. In the United States, approximately $50 \%$ of TSCI patients have their medical costs covered through a private insurer. Medicaid, a state-run medical insurance provider for financially disadvantaged patients, covers $28 \%$ of those having sustained a TSCI. The remaining population has their medical costs covered through Medicare or the Veterans Health Administration (VHA) ${ }^{[13]}$. The average cost for the initial injury and recovery phase, termed the acute phase, can run $\$ 142,366^{[12]}$. The majority of these charges will be covered through a patient's primary medical insurance. Most patients, with the exception of eligible military veterans through the VHA, are often left with high co-pays that place an additional undue financial burden on the recovery process. 


\section{Causes of Traumatic Spinal Cord Injury Since 2010 (NSCISC)}

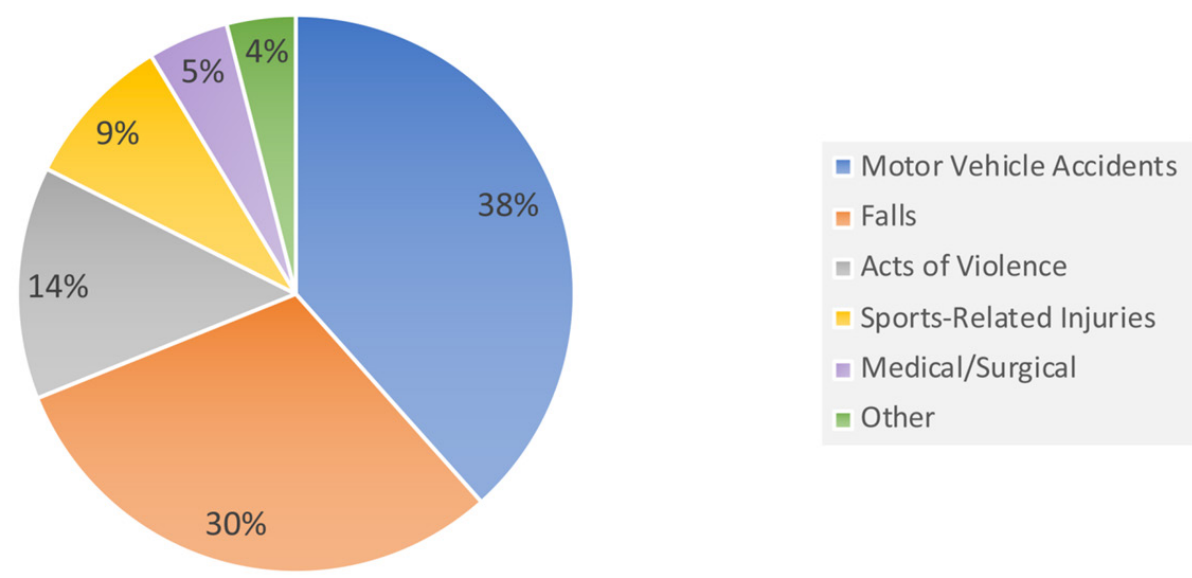

Figure 1. A pie chart illustrating the major causes of $\mathrm{TSCl}$ since $2010^{[2]}$ according to the NSCISC. The NSCISC estimates that the most common causes of $\mathrm{TSCl}$ include motor vehicle accidents (blue), mechanical falls (orange), and acts of violence (gray). Less commonly $\mathrm{TSCl}$ is caused by sports-related injuries (yellow), medical/surgical causes (pink), and other miscellaneous causes not previously listed (green). TSCl: traumatic spinal cord injury; NSCISC: National Spinal Cord Injury Statistical Center

Table 1. Percentage of patients with ASIA grade at ER discharge and resultant one year ASIA improvements

\begin{tabular}{|c|c|c|c|c|}
\hline ASIA Grade & Injury type & Definition Of ASIA Grade & $\begin{array}{l}\text { TSCI patients with ASIA } \\
\text { Grade at time of Discharge }\end{array}$ & $\begin{array}{l}\text { ASIA Grade one year improvement } \\
\text { rates }(\geq 1 \text { Grade level) })^{\star \star}\end{array}$ \\
\hline Grade A & Complete & Complete sensorimotor loss & $36.4 \%$ & $25.1 \%$ \\
\hline Grade B & Incomplete & $\begin{array}{l}\text { Complete motor loss with incomplete } \\
\text { sensory loss }\end{array}$ & $13.8 \%$ & $71.1 \%$ \\
\hline Grade C & Incomplete & $\begin{array}{l}\text { Motor function is preserved, but more than } \\
50 \% \text { of key muscles below the neurological } \\
\text { level have a muscle grade }<3\end{array}$ & $11.9 \%$ & $78.8 \%$ \\
\hline Grade D & Incomplete & $\begin{array}{l}\text { Motor function is preserved but the at } \\
\text { least } 50 \% \text { of key muscles below the } \\
\text { neurological level have a muscle grade } \geq 3\end{array}$ & $37.6 \%$ & $14.1 \%$ \\
\hline Grade E & Normal & Motor and sensory functions are normal & $0.3 \%$ & N/A \\
\hline
\end{tabular}

ASIA: American spinal injury association; *: within each of the ASIA grade rows, there is the percentage of total TSCI patients at the time of hospital discharge with that specific ASIA grade injury out of all TSCI patients; ER: emergency room; TSCI: traumatic spinal cord injury; **: percentage of patients who have improved $\geq 1$ ASIA grades from their original ASIA grade assignment (column 1) at one year postdischarge. Grade B and C injuries have the highest chance of improvements at $71.1 \%$ and $78.8 \%$, respectively ${ }^{[26,27]}$

Evidence demonstrates that surgical intervention within the first $72 \mathrm{~h}$ post-injury is both a key prognostic and cost-determining factor in the context of TSCI. Surgical intervention within this crucial window has been shown to directly correlate with a decreased hospital length of stay (LOS) and subsequent decreased medical costs ${ }^{[15,16]}$. If surgical intervention is received within $72 \mathrm{~h}$ following the initial injury, hospitals were found to save an average of $\$ 14,000$ on resource utilization. Additionally, patients were found to have a greater chance of neurological recovery and were spared approximately $\$ 45,000$ in medical costs. A prospective cohort study investigating the relationship between the delay of surgical decompression following TSCI and neurological recovery found that decompression within the first $24 \mathrm{~h}$ more than doubled the chance of recovery of a 2 ASIA grade TSCI as compared to those who received spinal cord decompression outside of this $24 \mathrm{~h}$ window ${ }^{[1,17]}$. This rapid surgical turnaround within $24 \mathrm{~h}$ was found to be just as safe ${ }^{[18]}$. However, this crucial window presents an access to care issue for those living in rural areas in which there is a high prevalence of TSCI, but low rate of hospitalization with subsequent inflated 


\section{Extent of Traumatic Spinal Cord Injury Since 2010 (NSCISC)}

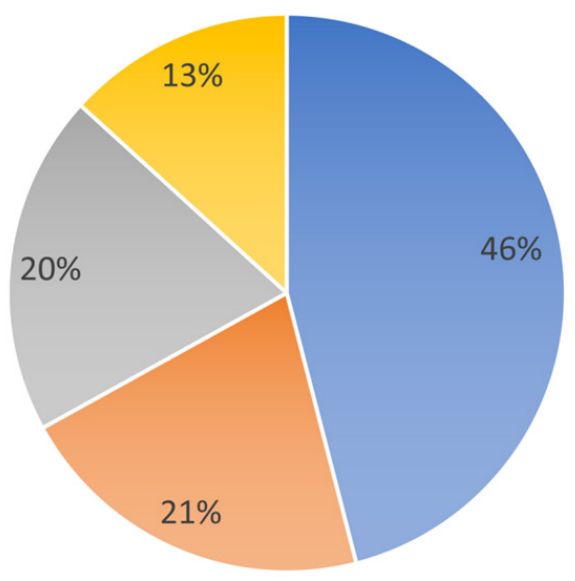

- Incomplete Tetraplegia

= Incomplete Paraplegia

- Complete Paraplegia

- Complete Tetraplegia

Figure 2. A pie chart illustrating the extent of injury following TSCI since $2010^{[2]}$ according to the NSCISC. The NSCISC estimated that nearly half of all TSCI resulted in the extent of injury known as incomplete tetraplegia (blue). Incomplete and complete paraplegia were similar in prevalence following $\mathrm{TSCl}$ (represented by orange and gray, respectively) while complete tetraplegia (yellow) was the least common extent of injury following TSCl as compared to the other major extent of injury categories. TSCl: traumatic spinal cord injury; NSCISC: National Spinal Cord Injury Statistical Center

healthcare costs ${ }^{[12]}$. Sparsely located hospitals in rural areas ill-equipped to manage complex TSCIs may underlie the delayed care observed in rural areas ${ }^{[12,19]}$.

\section{HOSPITAL LENGTH OF STAY FOLLOWING TRAUMATIC SPINAL CORD INJURY}

The average hospital LOS following a TSCI was found to be approximately 12 days, twice as long as patients without TSCI. Interestingly, patients between the ages of 18-29 averaged 13.5 days in the hospital, while elderly patients (over 60 years old) averaged only 10 days. This is a surprising observation that can be attributed to younger age being a major risk factor for more severe forms of TSCI ${ }^{[12]}$. Surgical intervention is often necessary for severe TSCIs and is significantly more expensive than conservative medical management. In a study conducting a cost/benefit analysis in elderly patients with odontoid (C1-C2) fractures, it was found that the cost of surgical intervention was approximately $\$ 50,000$ per patient, while the cost of medical management alone was more akin to $\$ 30,000$ per patient. When considering the options between surgical and medical management, it is important to note that patients between the ages of 6585 had a favorable increase in quality adjusted life years (QALY) following surgical management. These patients' qualities of life improved following surgical management to offset the high costs of care. Patients over the age of 85 did not see the favorable QALY improvement from surgical intervention, suggesting this population would have the greatest cost-benefit from conservative medical management as compared to surgical intervention ${ }^{[20]}$. The ASIA score can be utilized as a determinant of emergency room (ER) cost as well $^{[15,21]}$. Using this information, TSCI surgical hospital costs can be lowered by trying to target certain age groups (under 85 ) and by attempting surgical intervention sooner ${ }^{[2]}$.

\section{RECOVERY AND LONG-TERM DISABILITY FOLLOWING TRAUMATIC SPINAL CORD INJURY}

\section{Post-injury rehabilitation}

TSCI recovery is divided into three major phases: acute, post-acute, and chronic ${ }^{[23,24]}$. The acute phase is marked by post-injury care received in the hospital, while post-acute and chronic phases are distinguished 


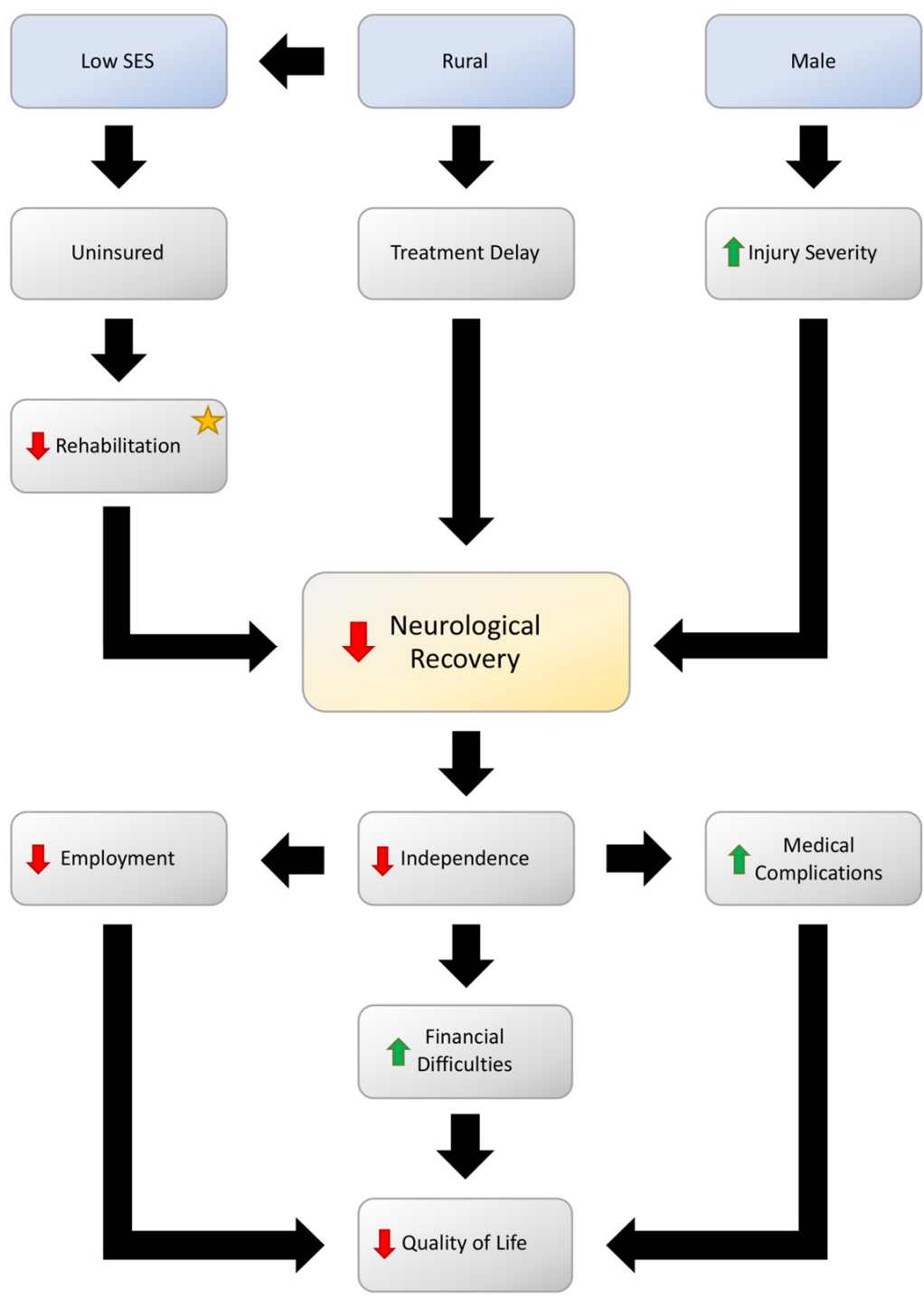

Figure 3. A flowchart illustrates the primary risk factors for a TSCI (blue) and the obstacles TSCl patients may face throughout their lives. Decreased neurological recovery (yellow) is the factor that has the greatest negative impact on a patient. Access to rehabilitation (star) is the only modifiable attribute shown that can reduce the cascade of negative events leading to a decreased patient quality of life. SES: socioeconomic status; TSCl: traumatic spinal cord injury

through post-injury care delivered in an outpatient setting ${ }^{[24]}$. While the timeframe of each of these phases varies, neurological recovery has been found to occur during the acute and post-acute phases. This crucial recovery period has been found to last between 12-18 months, with the majority of improvement observed in the first 3 months post-injury ${ }^{[25]}$. During the acute and post-acute phases, rehabilitation seeks maximize neurological recovery as measured by the ASIA grade ${ }^{[26,27]}$. A patient will enter the chronic phase when they have reached their maximum neurological recovery; therefore, priorities in the chronic phase shift to minimizing common long-term TSCI co-morbidities and normalizing a patient's new post-injury standard of living ${ }^{[28]}$. The neurological recovery and the quality of life of the TSCI patients are dependent on various primary risk factors and the obstacles that they may face throughout their lives [Figure 3].

To date, few studies have examined the recovery rates corresponding with the time between TSCI and initiation of rehabilitation ${ }^{[23]}$. Regardless, studies have shown TSCI patients having access to rehabilitation corresponds to better outcomes and a greater chance for patients to reclaim their roles as active members of 
the society ${ }^{[29]}$. Despite its importance, discrepancies of who should receive rehabilitation continue to exist. A study investigating rehabilitation rates in patients with TSCI examined patients with private insurance, government insurance (Medicare/Medicaid), and the uninsured. Patients with private insurance were referred to rehabilitation services $84.6 \%$ of the time, while government and the uninsured were referred rehabilitation $55.5 \%$ and $55.2 \%$ of the time, respectively, despite both populations having similar injury severities. This study also found that patients with government insurance had an average LOS of 12 days longer than both privatized insurance and those who remain uninsured. However, the explanations are varied. Claridge et al ${ }^{[28]}$ hypothesizes that uninsured patients are simply rejected from most rehabilitation facilities and are inevitably sent home, while privately insured patients are transferred to rehabilitation facilities as soon as possible. Patients with government insurance are kept in the hospital while case management explores potential options, explaining their increased $\operatorname{LOS}^{[28]}$. Although not surprising, these results give rise for concern. Increased time between injury and rehabilitation has been associated with decreased long-term quality of life and a decreased ability to live independently; thus, raising the long-term cost of care for these individuals. Rehabilitation teaches patients to prevent secondary health complications, maximizing function and work towards long term healthy lifestyles ${ }^{[23]}$.

\section{Long-term complications of a traumatic spinal cord injury}

In the years following a TSCI, patients face a risk of several severe co-morbidities. Most fatal complications are due to urinary tract infections (UTIs), sepsis due to pneumonia, and pressure ulcers (in those with T1-S5 injuries $)^{[30,31]}$. A medium-sized cohort study found that $47.6 \%$ of TSCI participants were treated for a UTI, $33.8 \%$ were treated for pneumonias, $27.5 \%$ for depression, and $19.7 \%$ for a decubitus ulcers ${ }^{[32]}$. Characterized as a "never event", almost one third of all pressure ulcers are seen in paralyzed patients. The estimated cost for treating a stage IV pressure ulcer (an ulcer that extends into the underlying bone and muscle $e^{[33]}$ ) is approximately $\$ 124,000-\$ 129,000$ per instance ${ }^{[34,35]}$. Sepsis, the second most expensive of the above listed comorbidities in TSCI patients, was found to cost around $\$ 27,000$ per stay in the intensive care unit (ICU). When broken down to the cost by day, the cost of sepsis in the ICU per day in the United States was just over $\$ 4,500^{[36]}$. As suggested in the data from the medium sized cohort, TSCI paralysis is a risk factor for increased UTI rates ${ }^{[32,37]}$. The most common of the comorbidities and the least expensive, it cost around $\$ 8,300$ per hospital treatment ${ }^{[37]}$.

\section{Post-injury re-hospitalization rates}

Patients within the first year following a TSCI are at a significant risk for re-hospitalization. One study estimates a re-hospitalization rate between $36 \%-45 \%$ in the first year post-injury, decreasing to a $30 \%$ rehospitalization risk in subsequent post-injury years ${ }^{[38]}$. The authors of a 2015 study investigating emergency room visits (ERV) and emergency re-hospitalizations (ERH) in chronic TSCI patients found that 37\% of participants had at least $1 \mathrm{ERV}$ in the last year, with half of those visits progressing to an $\mathrm{ERH}^{[39]}$. The average hospital LOS for these patients was found to be 21 days ${ }^{[40]}$. An additional study found that the only modifiable risk factor for a TSCI patient ERH is lower functional independence following initial rehabilitation ${ }^{[41]}$. Lack of independence is an important issue for uninsured TSCI patients, who encompass $12 \%$ of the TSCI population ${ }^{[1]}$. As stated previously, most uninsured TSCI patients forego rehabilitation, causing decreased functional independence and a subsequent increased risk of medical emergencies ${ }^{[42]}$.

TSCI patients re-admitted to a hospital post-injury experience a wide range of costs that are dependent on their co-morbidities. A 2018 study followed a cohort of TSCI patients over a decade while analyzing their use of health care services over that period. This study found that a combined $\$ 49.4$ million was spent on health care services over this 10-year span for all 303 participants. Interestingly, two-thirds of those costs were utilized by only $16.5 \%$ of the study population (termed High Utilizers), with each individual charging $\$ 51,860$ per year. High Utilizers had an ERH 2.6 times per year with an average LOS of 9.6 days, often being treated for multiple co-morbidities. High Utilizers were commonly male, of a racial minority, of low 
socio-economic status, with high-grade TSCI, and experienced frequent pressure ulcers. In contrast, 53\% of chronic TSCI patients were considered Low Utilizers. These patients on average visited the ED 0.1 times per year and only stayed in the hospital 0.3 days per year ${ }^{[38]}$.

\section{MILITARY VETERANS SUSTAINING TRAUMATIC SPINAL CORD INJURY}

According to the department of veterans affairs, the VHA is the largest network of TSCI care in the country, with over 1,200 integrated healthcare facilities distributed throughout the country. As of 2018, there are over 19 million United States military veterans, and approximately 9.15 million of those veterans are enrolled in the veterans affairs (VA) health care system; making the VHA a healthcare provider for approximately $2.8 \%$ of the American population ${ }^{[43,44}$. In order for a military veteran to qualify for VAsponsored healthcare, they must have served under active duty and have been honorably discharged. Veterans sustaining a TSCI while in active military service are eligible for monthly disability compensation in addition to the healthcare coverage that all VHA-eligible veterans receive ${ }^{[45]}$. Veterans who are injured in connection to their military service are entitled to comprehensive healthcare coverage with zero monetary responsibility falling onto the patient ${ }^{[46]}$. The VHA provides an interesting perspective on health care resource allocation due to eligible veterans being the sole TSCI population in the United States with no financial responsibility for their post-injury TSCI care.

\section{Traumatic spinal cord injury costs in the veterans affairs health care system}

According to the VHA, there are approximately 26,000 TSCI patients who are eligible to receive VHAsponsored treatment, half of which chose to undergo specialty treatment within the VA health care system $^{[45]}$. The first 12 months post-injury were found to be the costliest, with the average patient being charged $\$ 606,349$ within the first year. Patients were then charged an average of $\$ 92,454$ annually for longterm care ${ }^{[47]}$. However, these charges can vary greatly depending on the severity and extent of the injury. Veterans with C1-C4 tetraplegia accrue an average of $\$ 1,064,716$ in costs within the first year with $\$ 184,891$ annually, while veterans who still retain some motor function at all levels average $\$ 347,484$ in costs within the first year and $\$ 42,206$ annually ${ }^{[48]}$.

\section{Prescription medication coverage for those with TSCI}

Considering the high cost of many prescription medications, $88 \%$ of veterans with TSCI obtain prescription medication coverage through the VHA. The remaining $12 \%$ utilize either a combination Medicare Part D \& VHA (9.5\%) or Part D alone (2.8\%). This trend is likely to continue as most veterans with TSCI are exempt from medication co-payments through the VHA. Patients sustaining a TSCI or secondary comorbidity (i.e., pressure ulcer, UTI, diabetes) were found to rely less on Medicare Part D and more on the VHA for their prescription medication needs ${ }^{[49]}$.

\section{UNEMPLOYMENT AND BANKRUPTCY FOLLOWING TRAUMATIC SPINAL CORD INJURY}

It is unsurprising that TSCIs of all severities are one of the most debilitating injuries a person can experience, often causing significant undue financial $\operatorname{strain}^{[50]}$. Despite many TSCI patients having a desire and capability to work, data show that only $35 \%$ of those having sustained TSCI eventually return to active employment ${ }^{[51-53]}$. Five years post-injury, $25 \%$ of these patients were found to file for bankruptcy ${ }^{[54]}$. TSCIs decrease the quality of life in patients due to their consequent inability to work and increased healthcare $\operatorname{costs}^{[55]}$. Following a TSCI, mobility/physical impairments and incontinence issues may limit the type of work available to TSCI patients ${ }^{[56,57]}$. Following a TSCI, skilled labor jobs may no longer be an option and many patients unable to return to their old jobs are forced to find new avenues of employment ${ }^{[58,59]}$. Realizing this difficulty, the Rehabilitation Act of 1973 was amended in 1992 to include supported employment (SE), which promotes disabled persons to return to the workforce. SE encourages those with significant disability to find jobs with competitive pay and have supportive services provided to those that in need ${ }^{[60]}$. 


\section{Effectiveness of the supported employment initiative in veterans with TSCI}

In 2012, a randomized multisite study investigated the effectiveness of a SE rehabilitation program in aiding military veterans with TSCI find post-injury employment. The initial results showed that veteran participants were $11.4 \times$ more likely to find employment as compared to veterans without any form of rehabilitation program ${ }^{[00]}$. Two years later, a follow-up study was performed by the same investigators assessing the long-term performance of the previously studied SE rehabilitation program. The results showed that veterans were $30.8 \%$ more likely to achieve employment; however, veterans were significantly more likely to achieve employment within the first 12 months after their TSCI compared to those who waited longer than a year ${ }^{[61]}$.

In the same year as the 2-year follow-up study, a cost-effectiveness analysis was performed on the $\mathrm{SE}$ rehabilitation program for veterans with TSCI. Each participant received approximately $35 \mathrm{~h}$ of rehabilitation services costing $\$ 1,821$ on average. The costs associated with the program were then compared to the quality of life improvement self-reported by each of the participants. The results showed that participants in the SE rehabilitation program had marginally reduced societal costs compared to the control group. But these results, coupled with an insignificant difference in quality of life improvement, led to the determination that the SE rehabilitation program was not cost-effective as compared to standard care $^{[62]}$.

\section{Bankruptcy prevalence in those having sustained a TSCI}

In the United States, the leading cause of bankruptcy is the inability to pay medical bills ${ }^{[63]}$. A study comparing the risk of bankruptcy before and after TSCI found that patients sustaining a TSCI have a 3.5\% chance of bankruptcy in the first five years post-injury. Interestingly, those with private insurance were twice as likely to file for bankruptcy as compared to those with Medicaid. The authors attributed this finding to private insurance patients accruing additional debts pre-injury that they can no longer be paid back (i.e., car, mortgage, etc. ${ }^{[64]}$. Race and income were also found play an important role for those returning to work post-injury. For caucasian patients it took a median of 566 days to return to work. However, their non-Caucasian counterparts took 1382 days to return to work, almost 2.5 times slower. Considering income, higher income patients in the upper 75th percentile returned to work in 557 days. In contrast, TSCI patients in the lower 25th percentile of income returned to work over 200 days later than their higher income counterparts. Phillips et al. ${ }^{[58]}$ attributed this delay to lower paying jobs often requiring skilled physical labor, causing an obvious barrier to TSCI patients.

Following a TSCI, patients report unemployment and financial difficulties as primary factors contributing to unhappiness, to a greater extent than the extent of their disability. Employment gives these patients a sense of both purpose and financial independence ${ }^{[57]}$. Patients with greater levels of social support, community integration and higher levels of education were more likely to gain steady employment ${ }^{[65,66]}$. TSCI may leave patients emotionally drained and separated from their social lives ${ }^{[67]}$. Prolonged unhappiness can exacerbate a variety of mental illnesses, with studies showing that $18 \%-37 \%$ of TSCI patients presented with signs of major depressive disorder (MDD ${ }^{[56]}$. Financial stressors such as job loss, financial crisis, and inability to pay bills are found in $31.2 \%$ of those with $\mathrm{MDD}^{[68,69]}$. Patients following a TSCI may additionally have altered decision making capabilities due to the increased incidence of MDD $^{[7]}$.

\section{CONCLUSION}

TSCI is a lifelong costly injury for both hospital systems and the patient. Fast access to decompression surgery and early rehabilitation has been shown to improve injury outcomes. Although access to rehabilitation can be difficult through certain forms of insurance, it is critical in TSCI care. Lack of rehabilitation services has been associated with greater levels of comorbid secondary health conditions. 
Condition's such as UTI, sepsis, and pressure ulcers account for higher health care cost utilization by TSCI patients. Reduction of secondary heath conditions is one of the few areas that can be modified in TSCI patients. Implementing rehabilitation and education about secondary health conditions for all TSCI patients would save both hospitals and patients money. These savings would allow for allocation of healthcare resources to other areas.

\section{DECLARATIONS}

\section{Authors' contributions}

Conceptualized the theme and conducted the literature review process: Merritt CH, Taylor MA, Yelton CJ Contributed to preparation of the manuscript, interpretation of subtopics, preparation figures, and revision of the manuscript; and approved the final version to be published: Merritt $\mathrm{CH}$, Taylor MA, Yelton CJ, Ray SK

\section{Availability of data and materials}

Not applicable.

\section{Financial support and sponsorship}

The work was supported in part by an investigator-initiated research grant (SCIRF-2015-I-01) from South Carolina Spinal Cord Injury Research Fund (Columbia, SC, USA), and earlier R01 grants (CA-091460; NS057811) from the National Institutes of Health (Bethesda, MD, USA).

\section{Conflicts of interest}

All authors declared that there are no conflicts of interest.

\section{Ethical approval and consent to participate}

Not applicable.

\section{Consent for publication}

Not applicable.

\section{Copyright}

(c) The Author(s) 2019.

\section{REFERENCES}

1. James SL, Theadom A, Ellenbogen RG, Bannick MS, Montjoy-Venning W, et al. Global, regional, and national burden of traumatic brain injury and spinal cord injury, 1990-2016: a systematic analysis for the Global Burden of Disease Study 2016. Lancet Neurol 2019;18:56-87.

2. National Spinal Cord InjuryStatistical Center. Spinal Cord Injury Facts and Figures at a Glance. J Spinal Cord Med 2013;36:568-9.

3. Jain NB, Ayers GD, Peterson EN, Harris MB, Morse L, et al. Traumatic spinal cord injury in the United States, 1993-2012. JAMA 2015;313:2236-43.

4. Ge L, Arul K, Ikpeze T, Baldwin A, Nickels JL, et al. Traumatic and Nontraumatic Spinal Cord Injuries. World Neurosurg 2018;111:e142-8.

5. Devivo MJ. Epidemiology of traumatic spinal cord injury: Trends and future implications. Spinal Cord 2012;50:365-72.

6. Frontera JE, Mollett P. Aging with Spinal Cord Injury: An Update. Phys Med Rehabil Clin N Am 2017;28:821-8.

7. Kirshblum S, Waring W. Updates for the international standards for neurological classification of Spinal Cord Injury. Phys Med Rehabil Clin N Am. 2014;25:505-17.

8. Smith EM, Boucher N, Miller WC. Caregiving services in spinal cord injury: A systematic review of the literature. Spinal Cord 2016;54:562-9.

9. Ma VY, Chan L, Carruthers KJ. Incidence, prevalence, costs, and impact on disability of common conditions requiring rehabilitation in the united states: Stroke, spinal cord injury, traumatic brain injury, multiple sclerosis, osteoarthritis, rheumatoid arthritis, limb loss, and back pa. Arch Phys Med Rehabil 2014;95:986-95. 
10. Groah SL, Charlifue S, Tate D, Jensen MP, Molton IR, et al. Spinal cord injury and aging challenges and recommendations for future research. Am J Phys Med Rehabil 2012;91:80-93.

11. Selvarajah S, Schneider EB, Black JH, Abularrage CJ, Dhiman N, et al. The Burden of Acute Traumatic Spinal Cord Injury among Adults in the United States: An Update. J Neurotrauma 2013;31:228-38.

12. Mahabaleshwarkar R, Khanna R. National hospitalization burden associated with spinal cord injuries in the United States. Spinal Cord 2014;52:139-44.

13. Cord S, Model I. 2014 Annual Report Complete Public Version; 2014.

14. Eckert MJ, Martin MJ. Trauma: Spinal Cord Injury. Surg Clin North Am 2017;97:1031-45.

15. Parent S, Bourassa-Moreau É, Feldman DE, Thompson C, Mac-Thiong J-M. Does Timing of Surgery Affect Hospitalization Costs and Length of Stay for Acute Care following a Traumatic Spinal Cord Injury? J Neurotrauma 2012;29:2816-22.

16. Medress Z, Arrigo RT, Gephart MH, Zygourakis CC, Boakye M, et al. Cervical Fracture Stabilization within 72 Hours of Injury is Associated with Decreased Hospitalization Costs with Comparable Perioperative Outcomes in a Propensity Score-Matched Cohort. Cureus 2015;7:e244.

17. Fehlings MG, Vaccaro A, Wilson JR, Singh A, W Cadotte D, et al. Early versus delayed decompression for traumatic cervical spinal cord injury: results of the Surgical Timing in Acute Spinal Cord Injury Study (STASCIS). PLoS One 2012;7:e32037.

18. Liu J-M, Long X-H, Zhou Y, Peng H-W, Liu Z-L, et al. Is Urgent Decompression Superior to Delayed Surgery for Traumatic Spinal Cord Injury? A Meta-Analysis. World Neurosurg 2016;87:124-31.

19. Hamilton R, Driver S, Noorani S, Callender L, Bennett M, et al. Utilization and access to healthcare services among communitydwelling people living with spinal cord injury. J Spinal Cord Med 2017;40:321-8.

20. Barlow DR, Higgins BT, Ozanne EM, Tosteson ANA, Pearson AM. Cost Effectiveness of Operative Versus Non-Operative Treatment of Geriatric Type-II Odontoid Fracture. Spine (Phila Pa 1976) 2016;41:610-7.

21. Dukes EM, Kirshblum S, Aimetti AA, Qin SS, Bornheimer RK, et al. Relationship of American Spinal Injury Association Impairment Scale Grade to Post-injury Hospitalization and Costs in Thoracic Spinal Cord Injury. Neurosurgery 2018;83:445-51.

22. Chan BCF, Craven BC, Furlan JC. A scoping review on health economics in neurosurgery for acute spine trauma. Neurosurg Focus 2018;44:E15.

23. Burns AS, Marino RJ, Kalsi-Ryan S, Middleton JW, Tetreault LA, et al. Type and Timing of Rehabilitation Following Acute and Subacute Spinal Cord Injury: A Systematic Review. Glob Spine J 2017;7:175S-94S.

24. Gutenbrunner C, Blumenthal M, Geng V, Egen C. Rehabilitation Services Provision and Payment. Am J Phys Med Rehabil 2017;96:S35-40.

25. Fawcett JW, Curt A, Steeves JD, Coleman WP, Tuszynski MH, et al. Guidelines for the conduct of clinical trials for spinal cord injury as developed by the ICCP panel: spontaneous recovery after spinal cord injury and statistical power needed for therapeutic clinical trials. Spinal Cord 2007;45:190-205.

26. Marino RJ, Burns S, Graves DE, Leiby BE, Kirshblum S, et al. Upper- and lower-extremity motor recovery after traumatic cervical spinal cord injury: an update from the national spinal cord injury database. Arch Phys Med Rehabil 2011;92:369-75.

27. Aarabi B, Sansur CA, Ibrahimi DM, Simard JM, Hersh DS, et al. Intramedullary lesion length on postoperative magnetic resonance imaging is a strong predictor of ASIA impairment scale grade conversion following decompressive surgery in cervical spinal cord injury. Clin Neurosurg 2017;80:610-20.

28. Claridge JA, Croce MA, Weinberg JA, Forsythe RM, Miller C, et al. The real predictors of disposition in patients with spinal cord injuries. J Trauma 2006;60:178-86.

29. Gerszten PC, Witham TF, Clyde BL, Welch WC. Relationship between type of health insurance and time to inpatient rehabilitation placement for surgical subspecialty patients. Am J Med Qual 2001;16:212-5.

30. Sabharwal S, Palacios PA, Gavin-Dreschnack D, French DD, Campbell RR, et al. Health Care Costs for Patients With Chronic Spinal Cord Injury in the Veterans Health Administration. J Spinal Cord Med 2016;30:477-81.

31. Sweis R, Biller J. Systemic Complications of Spinal Cord Injury. Curr Neurol Neurosci Rep 2017;17:8.

32. Dryden DM, Saunders LD, Rowe BH, May LA, Yiannakoulias N, et al. Utilization of health services following spinal cord injury: A 6-year follow-up study. Spinal Cord 2004;42:513-25.

33. Edsberg LE, Black JM, Goldberg M, McNichol L, Moore L, et al. Revised National Pressure Ulcer Advisory Panel Pressure Injury Staging System. J Wound Ostomy Cont 2016;43:585-97.

34. Russo A, Steiner C, Spector W. Hospitalizations Related to Pressure Ulcers Among Adults 18 Years and Older, 2006: Statistical Brief \#64. Source: Healthcare Cost and Utilization Project (HCUP) Statistical Briefs [Internet]. Rockville (MD): Agency for Healthcare Research and Quality (US); 2006-2008 Dec.

35. Brem H, Maggi J, Nierman D, Rolnitzky L, Bell D, et al. High cost of stage IV pressure ulcers. Am J Surg 2010;200:473-7.

36. Arefian H, Heublein S, Scherag A, Brunkhorst FM, Younis MZ, et al. Hospital-related cost of sepsis: A systematic review. J Infect 2017;74:107-17.

37. Brown P, Ki M, Foxman B. Acute pyelonephritis among adults: cost of illness and considerations for the economic evaluation of therapy. Pharmacoeconomics 2005;23:1123-42.

38. Krause JS, Murday D, Corley EH, DiPiro ND. Concentration of Costs Among High Utilizers of Health Care Services Over the First 10 Years After Spinal Cord Injury Rehabilitation: A Population-based Study. Arch Phys Med Rehabil 2019;100:938-44.

39. Krause JS, Terza J V, Cao Y, Clark JMR. Emergency room visits and hospitalizations among participants with spinal cord injury. NeuroRehabilitation 2015;36:313-21.

40. Cord S, Model I. 2017 Annual Report - Public Version; 2017. Available from: https://www.nscisc.uab.edu/. [Last accessed on 10 Jul 2019]. 
41. McKinley W, Meade MA, Kirshblum S, Barnard B. Outcomes of early surgical management versus late or no surgical intervention after acute spinal cord injury. Arch Phys Med Rehabil 2004;85:1818-25.

42. Guilcher SJT, Munce SEP, Couris CM, Fung K, Craven BC, et al. Health care utilization in non-traumatic and traumatic spinal cord injury: a population-based study. Spinal Cord 2010;48:45-50.

43. National Center for Veterans Analysis and Statistics. VA Benefits \& Health Care Utilization. Available from: https://www.va.gov/ vetdata/docs/pocketcards/fy2019q1.PDF. [Last accessed on 10 Jul 2019].

44. United States Census Bureau. United States Population. Available from: https://www.census.gov/popclock/.

45. Department of Veterans Affairs, Office of Public Affairs Media Relations. Fact sheet: VA and spinal cord injury. US Government Printing Office Internet: bookstore.gpo.gov. Washington; 2012.

46. Foundation C\& DR. Veterans and Military Benefits (Part 1). Available from: http://s3.amazonaws.com/reeve-assets-production/ Veterans-Benefits-Part-1-8-17-18.pdf. [Last accessed on 10 Jul 2019].

47. Furlan JC, Gulasingam S, Craven BC. The Health Economics of the spinal cord injury or disease among veterans of war: A systematic review. J Spinal Cord Med 2017;40:649-64.

48. DeVivo M, Chen Y, Mennemeyer S, Deutsch A. Costs of Care Following Spinal Cord Injury. Top Spinal Cord Inj Rehabil 2011;16:1-9.

49. Stroupe KT, Hon AJ, Suda K, Raad J, Smith BM, et al. Evaluating the Use of Medicare Part D in the Veteran Population With Spinal Cord Injury/Disorder. Arch Phys Med Rehabil 2018;99:1099-107.

50. Kern SB, Hunter LN, Sims AC, Berzins D, Riekena H, et al. Understanding the Changing Health Care Needs of Individuals Aging With Spinal Cord Injury. Top Spinal Cord Inj Rehabil 2019;25:62-73.

51. Young AE, Murphy GC. A social psychology approach to measuring vocational rehabilitation intervention effectiveness. J Occup Rehabil 2002;12:175-89.

52. Tomassen PC, Post MW, van Asbeck FW. Return to work after spinal cord injury. Spinal Cord 2000;38:51-5.

53. Ottomanelli L, Lind L. Review of critical factors related to employment after spinal cord injury: Implications for research and vocational services. J Spinal Cord Med 2009;32:503-31.

54. Relyea-Chew A, Hollingworth W, Chan L, Comstock BA, Overstreet KA, et al. Personal bankruptcy after traumatic brain or spinal cord injury: the role of medical debt. Arch Phys Med Rehabil 2009;90:413-9.

55. Rivers CS, Fallah N, Noonan VK, Whitehurst DG, Schwartz CE, et al. Health Conditions: Effect on Function, Health-Related Quality of Life, and Life Satisfaction After Traumatic Spinal Cord Injury. A Prospective Observational Registry Cohort Study. Arch Phys Med Rehabil 2018;99:443-51.

56. Moreno A, Zidarov D, Raju C, Boruff J, Ahmed S. Integrating the perspectives of individuals with spinal cord injuries, their family caregivers and healthcare professionals from the time of rehabilitation admission to community reintegration: Protocol for a scoping study on SCI needs. BMJ Open 2017;7:1-9.

57. Kennedy P, Hasson L. Return-to-work intentions during spinal cord injury rehabilitation: An audit of employment outcomes. Spinal Cord 2016;54:141-4.

58. Phillips VL, Hunsaker AE, Florence CS. Return to work and productive activities following a spinal cord injury: The role of income and insurance. Spinal Cord 2012;50:623-6.

59. Miller LE, Herbert WG. Health and economic benefits of physical activity for patients with spinal cord injury. Clinicoecon Outcomes Res 2016;8:551-8.

60. Ottomanelli L, Goetz LL, Suris A, McGeough C, Sinnott PL, et al. Effectiveness of supported employment for veterans with spinal cord injuries: results from a randomized multisite study. Arch Phys Med Rehabil 2012;93:740-7.

61. Ottomanelli L, Barnett SD, Goetz LL. Effectiveness of supported employment for veterans with spinal cord injury: 2-year results. Arch Phys Med Rehabil 2014;95:784-90.

62. Sinnott PL, Joyce V, Su P, Ottomanelli L, Goetz LL, et al. Cost-effectiveness of supported employment for veterans with spinal cord injuries. Arch Phys Med Rehabil 2014;95:1254-61.

63. Himmelstein DU, Thorne D, Warren E, Woolhandler S. Medical Bankruptcy in the United States, 2007: Results of a National Study. Am J Med 2009;122:741-6.

64. Hollingworth W, Relyea-Chew A, Comstock BA, Overstreet JKA, Jarvik JG. The risk of bankruptcy before and after brain or spinal cord injury: a glimpse of the iceberg's tip. Med Care 2007;45:702-11.

65. Hilton G, Unsworth CA, Murphy GC, Browne M, Olver J. Longitudinal employment outcomes of an early intervention vocational rehabilitation service for people admitted to rehabilitation with a traumatic spinal cord injury. Spinal Cord 2017;55:743-52.

66. Murphy G, Middleton J, Quirk R, De Wolf A, Cameron ID. Prediction of employment status one year post-discharge from rehabilitation following traumatic spinal cord injury: an exploratory analysis of participation and environmental variables. J Rehabil Med 2009;41:1074-9.

67. Raghava N, Das BC, Ray SK. Neuroprotective effects of estrogen in CNS injuries: insights from animal models. Neurosci Neuroecon 2017;6:15-29.

68. Zürcher C, Tough H, Fekete C, SwiSCI Study Group. Mental health in individuals with spinal cord injury: The role of socioeconomic conditions and social relationships. PLoS One 2019;14:e206069.

69. Wang Y, Sareen J, Afifi TO, Bolton SL, Johnson EA, et al. A Population-Based Longitudinal Study of Recent Stressful Life Events as Risk Factors for Suicidal Behavior in Major Depressive Disorder. Arch Suicide Res 2015;19:202-17.

70. Sharp C, Monterosso J, Montague PR. Neuroeconomics: a bridge for translational research. Biol Psychiatry 2012;72:87-92. 